\title{
Digital Media Habits among Parent of Preschool Child Aged 2-6 Years in Semarang City, Indonesia
}

\author{
Tandiyo Rahayu ${ }^{1}$, Widya Hary Cahyati ${ }^{2}$, Lukman Fauzi ${ }^{3}$, Michael Yong Hwa Chia ${ }^{4}$, \\ Terence Buan Kiong Chua ${ }^{5}$, Hendri Hariyanto ${ }^{6}$, Anisa Wahyu Hardini ${ }^{7}$, \\ Farida Nurjanati Hardanis ${ }^{8}$ \\ \{tandiyorahayu@mail.unnes.ac.id ${ }^{1}$, widyahary27@mail.unnes.ac.id ${ }^{2}$, \\ lukman.ikm@mail.unnes.ac.id ${ }^{3}$ \} \\ Universitas Negeri Semarang, Semarang, Indonesia ${ }^{1,2,3}$
}

\begin{abstract}
Excessive daily use in digital media can increase screen addiction, obesity, sedentary behavior, metabolic disorders, poor sleep, and eyesight problems. The aim was to know digital media habits among parent of preschool child aged 2-6 years in Semarang City, Indonesia. It was a cross-sectional design. Collected data were analyzed with a descriptive approach. Most digital media at home were television (540) and mobile devices (e.g., smartphones, tablets) (537). Otherwise, video game devices (e.g., console and handheld gaming players, virtual reality headset) owned a few of them (50). Digital media use among parent of preschool child was more frequent on weekdays than weekends. The correlation of parents with digital media and interactions with children in the weekday was $49.91 \%$, and at the weekend was $57.37 \%$.
\end{abstract}

Keywords: digital media, habits, parent, preschool children.

\section{Introduction}

The utilization of digital technology is more associated with aggressive behavior, sleep problems, lack of physical activity, metabolic disorders, lack of attention, and obesity in preschool and school-age children [1]. The effect of the benefits of digital media must be greater than the impact of the harm caused to the holistic development of preschool children. Children tend to be passive when looking at a digital screen. Besides that, the use of digital media also contributed to increased physical activity and increased brain development [2]. Children's responses to supportive programming about increased physical activity are fun, designed for them, and encourage active participation after age 3 [3], [4]. Previous studies found that children who play video games actively can cause a mild to moderate increase in physical activity in a short period [5], [6].

Mobile device applications can be used to increase the physical activity of children outside their room, explore the world, and stimulate brain growth [7]. Quality content provided by children by parents can connect directly with off-screen experiences, increase physical activity, encourage active involvement with caregivers and 
peers, and support creative and imaginative play according to their age [8], [9]. Research in 2010 states that spending time watching commercial TV is significantly related to BMI and not related to watching TV time in non-commercial education [10], [11].

A 2009 study where they measured body fat and physical activity in preschoolers was associated with higher TV viewing behavior and body fat and showed this relationship did not significantly change when various levels of physical activity were also involved [12]. The most commonly reported side effects are impaired metabolic function, cardiology, understanding of learning, neurocognitive development, listening, and eyesight [13]. The choice of commercial TV is supported by sedentary behavior, which also displays unhealthy food advertisements and helps encourage them to get used to snacking, which has an impact on excess food intake in children [14], [15].

In the last five years, few descriptive studies have been represented in several Asian countries, which state that the screen time experienced by children has a significant influence on mobile devices, televisions, laptops, and other forms of digital media before they are elementary school. Because much research is far behind understanding the use of digital media among preschoolers, more research is needed before this issue becomes focused and sharper. The purpose was to know digital media habits among parent of preschool child aged 2-6 years in Semarang City, Indonesia

\section{Methods}

This research was a cross-sectional design approach. The study collects data about digital media habits among parent of preschool child aged 2-6 years in Semarang City, Indonesia. The tool used in this study is SMALLQ ${ }^{\mathrm{TM}}$. Surveillance of digitalMedia hAbits in earLy chiLdhood Questionnaire is an acronym for SMALLQ ${ }^{\mathrm{TM}}$ that is developed by the Singapore research team. This questionnaire is in the English language has been translated to Bahasa Indonesia under the procedures established by the World Health Organisation. This SMALLQ ${ }^{\mathrm{TM}}$ provides several questions regarding the demographic state of the participants (highest education attained) and their parents (such as age, quality, and duration of digital media use).

\section{Result and Discussion}

Characteristics of respondent among parent of preschool child aged 2-6 years in Semarang City, Indonesia can be seen based on age and education level. At age, the average age of parents of children was 33 years 6 months. Characteristics of education level of parents can be seen in the following figure. 


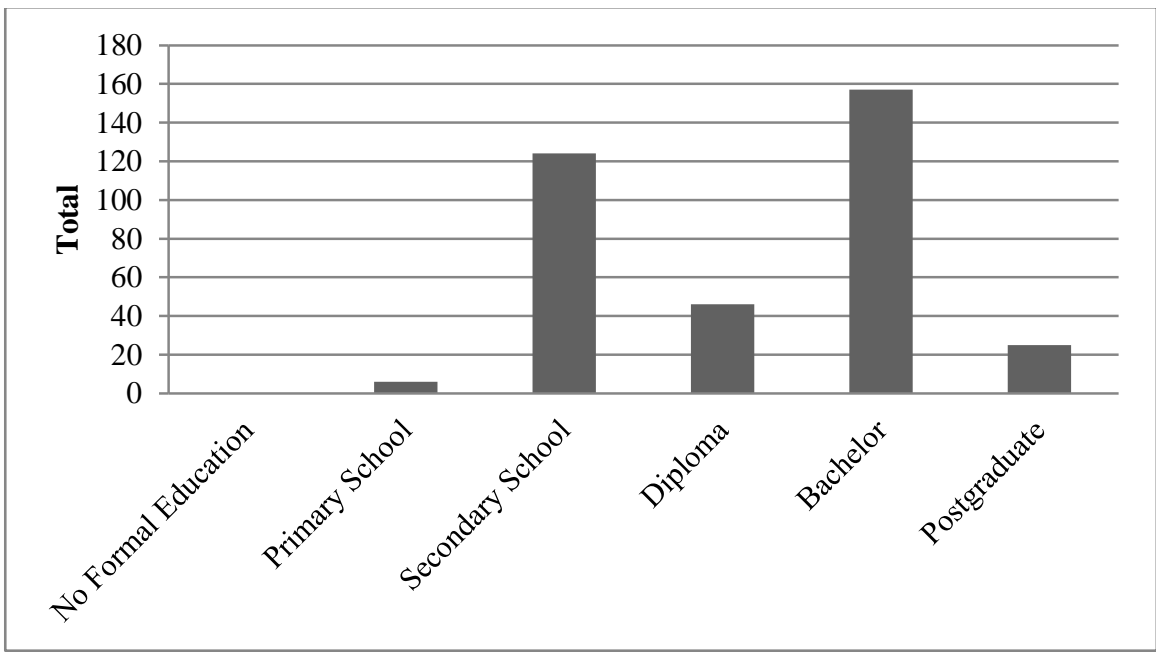

Fig. 1. Highest education attained of parent.

Based on the figure 1, it can be seen that there are no parents or guardians of children who do not have formal education, parents with an elementary school education were 6 people, middle school ie junior high school and high school as many as 124 people, diploma or academy and polytechnic education as many as 46 , bachelor were 157 people, and there were 25 people who were Masters or Doctor.

At the figure 2, most digital media at home of parent were television (540) and mobile devices (e.g. smartphones, tablets) (537). Otherwise, video game devices (e.g. console and handheld gaming players, virtual reality headset) owned a few of them was (50). Data digital environment at home of parent can be seen in the figure 2.

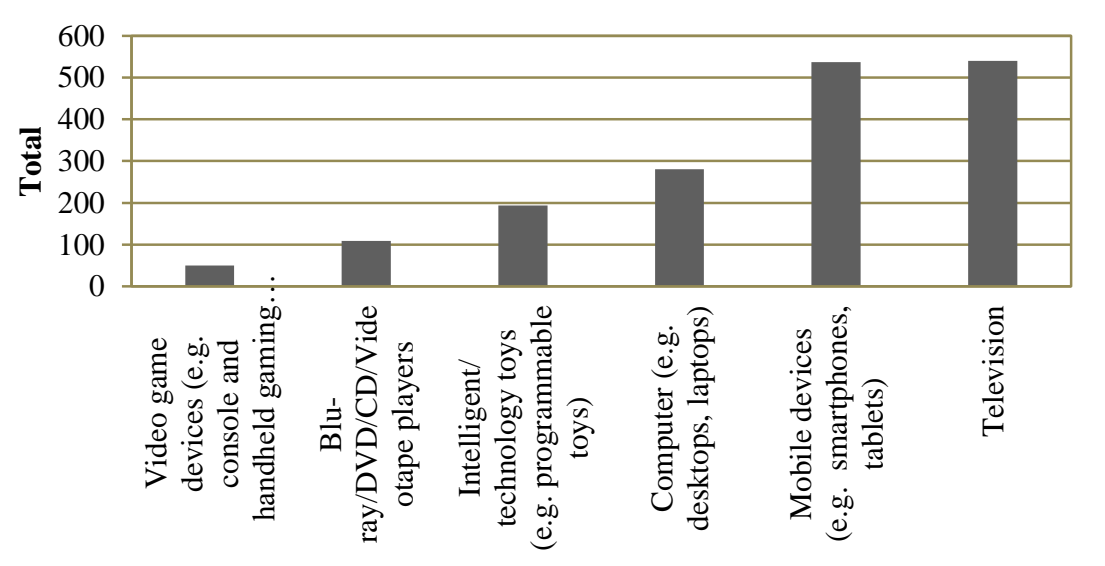

Fig. 2. Digital environment at home of parent 
Digital media devices such as (fixed screens (computers, televisions, laptops) and cellular screens (tablets, mobile devices, smartphones)) aimed at adults are now easily available for preschoolers, with or without sufficient supervision by parents [16]. Based on the figure 2, digital media mostly used were television and mobile devices. The use of digital media can have positive and negative impacts as well as brain development, body metabolism, nutritional intake, sleep quality, physical activity, and social interaction for healthy growth [1].

A systematic review in 2012 of the effect of watching TV and its impact on food consumption in children aged 2 to 6 years, stated that most of them reported negative effects by only watching TV for 1 hour/day [17]. The average having sedentary behavior among child between preschool age (2-5 years) were between 7 and 7.5 hours every day [18]. Consumption for watching television is most commonly found in children, where boys need the most television watching and playing video games, while girls use computers more than watching television [18].

Applications that can increase physical activity outside the room and be used to exploring the outside world are mobile devices [7]. Quality digital media loaded with quality content can support more active and imaginative play, encourage the active involvement of children with peers and caregivers, can connect screen experiences, and can stimulate brain growth [8], [9]. The intensity of the use of gadgets was high in $20 \%$ of preschool children during the weekday while almost doubling (39\%) during weekend [19]. The impact of electronic devices in children's bedrooms was often associated with less consumption of sleep minutes per night, partly due to the effect of the suppression of the hormone melatonin [20].

Table 2. The average time of parent's activity using digital media

\begin{tabular}{clll}
\hline No. & \multicolumn{1}{c}{ Activity } & Average time in the weekdays & Average time in the weekend \\
\hline 1 & Work & 2 hours 24 minutes & 53 minutes \\
2 & Entertainment & 1 hour 8 minutes & 1 hour 24 minutes \\
3 & Social Networking & 1 hour 24 minutes & 1 hour 24 minutes \\
4 & Personal Development & 1 hour 4 minutes & 1 hour 2 minutes \\
\hline
\end{tabular}

The average time of parent's using digital media on weekday (Monday-Friday) was 1 hour 13 minutes, meanwhile on weekend (Saturday and Sunday) was 1 hour 11 minutes with the usage detail on the table above. Experts says that the maximum time for social media usage is 30 minutes in a day, thus can lead to significant improvement in well-being [21]. The results shows that parent's activity on social media is exceed from the time limit.

Parents sedentary behaviour associated with sedentary behaviour in children, weekends has stronger significant association observed than on weekdays. In the result, prents has higher amounts of screen time at weekdays than on weekend. Study shows that higher parent's screen time was associated to children screen time, and the BMI of parent's also associated to children BMI [22]. Intuitively, comparing on weekend than weedays, all members of families with preschool children spend more free time together and share more activities [23]. Intervention to decrease parents screen time was needed to reduce sedentary habit and to promoting healthy weight on family. 
Based on the correlation of parents/guardians with digital media and interactions with children, on weekday (Monday-Friday) as many as $49.91 \%$ are used by parents/guardians to interact with children. As for the weekend (Saturday and Sunday) the average time parents/ guardians of children who are used to interact with children as much as $57.37 \%$. This shows that parents/guardians of children interact a lot like interactions with children when playing digital media on weekends rather than on weekdays.

The relationship between parents and child in screen time was stronger at weekends compared weekdays. The self-efficacy of parents towards limiting screen time and relationships with children illustrates that screen time on weekdays and weekends has a significant inverse correlation [24]. In line with previous research, the result show about the relationship of parent and child in screen time stronger at weekends than on weekdays [25]. Habits related to energy balance such as sedentary behavior and physical activity in children allow a variety of influencing variables such as the different parents behavior on weekdays and weekends ie on weekends parents might be closer to their children and engage in various stimulating behavior on improving health activities such as applying parents rules to watch TV, screen time, and doing physical activities between parents and children [24].

\section{Conclusion}

Most digital media at home of parent were television and mobile devices (e.g. smartphones, tablets). Otherwise, video game devices (e.g. console and handheld gaming players, virtual reality headset) owned a few of them. The duration for parents' usage of digital media on weekday was more frequent than on weekend. The interactions of parents with children when playing digital media was stronger or much more on weekends than on weekdays.

\section{Acknowledgments}

We would like to thank the Faculty of Sports Science, Universitas Negeri Semarang, Indonesia for the funding.

\section{References}

[1] R. Mustafaoğlu, E. Zirek, Z. Yasacı, and A. Razak Özdinçler, "The Negative Effects of Digital Technology Usage on Children's Development and Health," Addicta Turkish J. Addict., vol. 5, no. 2, 2018.

[2] M. Ponti et al., "Le temps d'écran et les jeunes enfants: Promouvoir la santé et le développement dans un monde numérique," Paediatr. Child Heal., vol. 22, no. 8, pp. 461-477, 2017.

[3] A. R. Lauricella, E. Wartella, and V. J. Rideout, "Young children's screen time: The complex role of parent and child factors," J. Appl. Dev. Psychol., vol. 36, pp. 11-17, 2015. 
[4] D. R. Anderson and K. G. Hanson, "From blooming, buzzing confusion to media literacy: The early development of television viewing," Dev. Rev., vol. 30, no. 2, pp. 239-255, 2010.

[5] L. M. Vanderloo, "Screen-viewing among preschoolers in childcare: A systematic review," BMC Pediatr., vol. 14, no. 1, 2014.

[6] J. Van 'T Riet, R. Crutzen, and A. S. Lu, "How Effective Are Active Videogames among the Young and the Old? Adding Meta-analyses to Two Recent Systematic Reviews," Games Health J., vol. 3, no. 5, pp. 311-318, 2014.

[7] J. Marsh et al., "Exploring Play and Creativity in Pre- - Schoolers ' Use of Apps: A Report for Early Years Practitioners," Technol. Play, p. 203, 2015.

[8] NAEYC, "Technology and Interactive Media as Tools in Early Childhood Programs Serving Children from Birth through Age 8," Children, no. January, pp. 1-15, 2012.

[9] L. M. Takeuchi, "Families matter : Designing media for a digital age," no. June, p. 60, 2011.

[10] F. J. Zimmerman and J. F. Bell, "Associations of television content type and obesity in children," Am. J. Public Health, vol. 100, no. 2, pp. 334-340, 2010.

[11] N. Shenouda, "Swap Screen Time for Physical Activity," no. 5, pp. 11-12, 2012.

[12] D. M. Jackson, K. Djafarian, J. Stewart, and J. R. Speakman, "Increased television viewing is associated with elevated body fatness but not with lower total energy expenditure in children," Am. J. Clin. Nutr., vol. 89, no. 4, pp. 10311036, 2009.

[13] E. Bozzola et al., "Media devices in pre-school children: The recommendations of the Italian pediatric society," Ital. J. Pediatr., vol. 44, no. 1, pp. 1-5, 2018.

[14] V. C. Strasburger et al., "Policy statement - Children, adolescents, obesity, and the media," Pediatrics, vol. 128, no. 1, pp. 201-208, 2011.

[15] M. Hingle and D. Kunkel, "Childhood Obesity and the Media," Pediatr. Clin. North Am., vol. 59, no. 3, pp. 677-692, 2012.

[16] U. Nalika, "Mobile Device Usage Among Young Kids: A Southeast Asia Study," Asianparent Insights Mob., no. November, pp. 1-61, 2014.

[17] C. Ford, D. Ward, and M. White, "Television viewing associated with adverse dietary outcomes in children ages 2-6," Obes. Rev., vol. 13, no. 12, pp. 11391147, 2012.

[18] T. A. Barnett and A. S. Kelly, "Sedentary Behaviors in Today' s Youth :," AHA Sci. Statement, pp. 142-159, 2018.

[19] S. Asl and E. Manjuvani, "Usage of electronic gadgets among preschool children," Int. J. Home Sci., vol. 5, no. 2, pp. 1-5, 2019.

[20] D. Hill et al., "Media and young minds," Pediatrics, vol. 138, no. 5, 2016.

[21] M. G. Hunt, R. Marx, C. Lipson, and J. Young, "No more FOMO: Limiting social media decreases loneliness and depression," J. Soc. Clin. Psychol., vol. 37, no. 10, pp. 751-768, 2018.

[22] W. S. F. Goncalves, R. Byrne, M. T. Viana, and S. G. Trost, "Parental influences on screen time and weight status among preschool children from Brazil: A crosssectional study," Int. J. Behav. Nutr. Phys. Act., vol. 16, no. 1, pp. 1-8, 2019. 
[23] D. Sigmundová, E. Sigmund, P. Badura, J. Voká, L. Trhlíková, and J. Bucksch, "Weekday-Weekend Patterns of Physical Activity and Screen Time in Parents and Their Pre-schoolers," BMC Public Health, vol. 16, no. 898, pp. 1-9, 2016.

[24] D. Sigmundová et al., "Weekday - Weekend Variations in Mother-/Father Child Physical Activity and Screen Time Relationship : A Cross-Sectional Study in A Random Sample of Czech Families with 5- to 12-year-old Children," Eur. J. Sport Sci., vol. 18, no. 8, pp. 1158-1167, 2018.

[25] R. Jago et al., "Cross-Sectional Associations between The Screen-Time of Parents and Young Children : Differences by Parent and Child Gender and Day of The Week," Int. J. Behav. Nutr. Phys. Act., vol. 11, no. 1, pp. 1-8, 2014. 